Document downloaded from:

http://hdl.handle.net/10251/81875

This paper must be cited as:

Mendez Lopez, M.; Pérez Hernández, E.; Juan, M.; Juan (2016). Learning in the navigational space: Age differences in a short-term memory for objects task Learning and Individual Differences. Learning and Individual Differences. 50:11-22. doi:10.1016/j.lindif.2016.06.028.

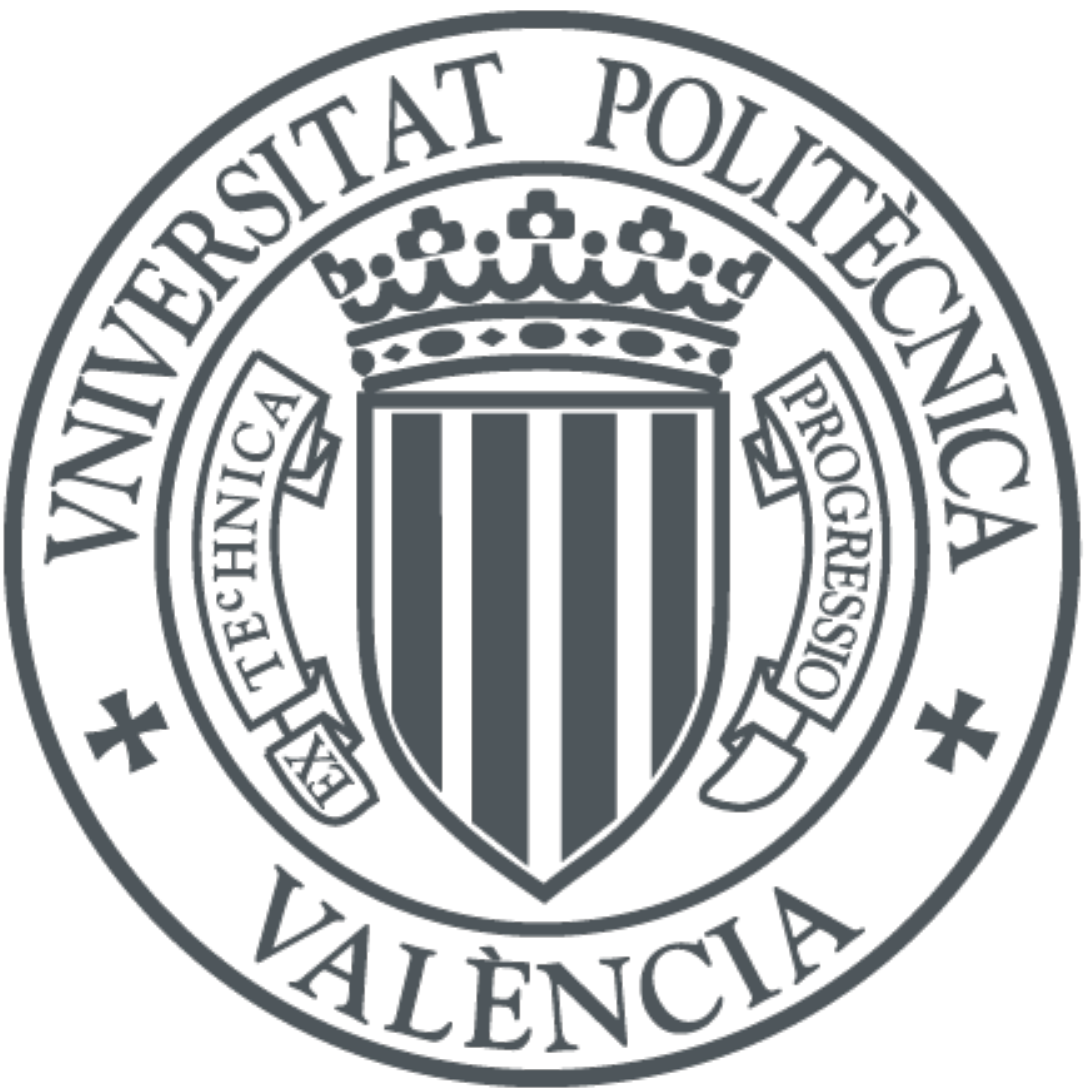

The final publication is available at

http://doi.org/10.1016/j.lindif.2016.06.028

Copyright Elsevier

Additional Information 


\title{
Learning in the Navigational Space: Age Differences in a Short-Term Memory for Objects Task
}

\author{
Magdalena Mendez-Lopez a ${ }^{*}$, Elena Perez-Hernandez ${ }^{\mathrm{b}}$, M.-Carmen Juan ${ }^{\circ}$ \\ a Departamento de Psicologia y Sociologia, Universidad de Zaragoza, Facultad de Ciencias Sociales y Humanas, Calle Atarazana s/n, 44003 Teruel, Spain \\ b Departamento de Psicologia Evolutiva y de la Educacion, Universidad Autónoma de Madrid, Facultad de Psicología, Calle Ivan Pavlov n6, 28049 Madrid, Spain \\ c Instituto Universitario de Automática e Informática Industrial, Universitat Politècnica de València, Camino de Vera, s/n., 46022, Valencia, Spain \\ * Corresponding author at: Universidad de Zaragoza, Departamento de Psicología y Sociología, Facultad de Ciencias Sociales y Humanas, Calle Atarazana s/n, 44003 \\ Teruel, Spain. \\ E-mail addresses: mmendez@unizar.es (M. Mendez-Lopez), elena.perezh@uam.es (E. Perez-Hernandez), mcarmen@ai2.upv.es, mcarmen@dsic.upv.es (M.-C. Juan).
}

\begin{abstract}
Age differences during development in visuospatial short-term memory (VSTM) in navigation have not been sufficiently proven. The performance of typically developing children from five age groups (from 5 to 10 years old) and one group of young adults (from 25 to 30 years old) was studied in an Augmented Reality navigational VSTM task that involved remembering the location of objects presented in increasing span lengths. The main results showed that navigational VSTM has not fully developed at the age of 9. The measures of performance significantly improved between ages 8 and 9. The overall performance on our navigational task was not influenced by gender, but there was a slight advantage for males when the difficulty of the task increased regarding the performance accuracy and the errors committed. The Augmented Reality task correlated with traditional spatial tests. Possible cognitive, biological, and methodological explanations for the findings are discussed.
\end{abstract}

Keywords: visuospatial memory; human navigation; augmented reality; age differences; sex differences

\section{Introduction}

Topographic memory is the capability to remember physical and spatial features of environments. The mental representation of the environment depends on distinct brain substrates that are based on the kind of space that is coded (i.e., body, near or far space) (Marshall \& Fink, 2001; Nemmi, Boccia, Piccardi, Galati, \& Guariglia, 2013; Rizzolatti, Berti, \& Gallese, 2000). Consequently, the brain representation of the body or personal space involves the physical body structure; the representation of the near or peripersonal space refers to the physical environment within reaching distance; and the representation of the far or extrapersonal space refers to the outside reaching distance, which is often referred to as the navigational space.

Much of human behaviour takes place in the navigational space, which includes different activities that we do while walking through an environment (e.g., searching for or locating objects, finding the way back to a room, and learning a route). The space can be processed and represented using two reference frames (Burgess, 2006): navigation related to the use of self-movement and internal cues, which is based on the egocentric reference frame; and navigation using external cues, which is based on the allocentric reference frame. Allocentric navigation uses mapping or geometrical calculations to locate places, whereas egocentric navigation is guided by one's body position in space. Egocentric and allocentric reference frames are encoded in different brain systems (reviewed in Knierim \& Hamilton, 2011). Hence, when the ability to navigate through the environment is impaired after brain damage, the consequences severely affect the person's daily functioning (Bouwmeester, van de Wege, Haaxma, \& Snoek, 2015; Ruggiero, Frassinetti, Iavarone, \& Iachini, 2014).

With regard to the impairment in navigational competencies, this type of deficit could appear during development in a selective disorder called developmental topographical disorientation (Bianchini et al., 2010, 2014; Iaria \& Barton, 2010; Iaria, Bogod, Fox, \& 
Barton, 2009). This disorder is characterized by impairment in spatial orientation skills but with no evident neurological or psychiatric disorders. The difficulties appear in early childhood, but the awareness of these difficulties arises in adolescence.

Furthermore, apart from the existence of specific developmental navigational disorder, children with poor spatial abilities are considered more likely to have learning difficulties that are associated with poor academic outcomes.the principal kind of spatial test that is related to academic performance is short-term memory for visuospatial information (Alloway \& Alloway, 2010). Thus, for example, Rourke (1993) described that children with learning disabilities had spatial-related deficits on a variety of specialized tests. Specifically, these spatial deficits have also been associated with non-verbal learning disability (Mammarella \& Cornoldi, 2014; Mammarella, Giofrè, Ferrara, \& Cornoldi, 2013), dyscalculia (Szucs, Devine, Soltesz, Nobes, \& Gabriel, 2013) and specific language impairment (Bavin, Wilson, Maruff, \& Sleeman, 2005).

Visuospatial short-term memory (VSTM) refers to the capacity to hold a small amount of information in mind in an active state for a short period of time. It is worthy to note that the vast majority of tests for the assessment of VSTM do not involve the participant's movement through the environment. The traditional procedures consist of static tasks that the person completes sitting in a chair (e.g., Alloway, 2012; Boringa et al., 2001; Kessels, van Zandvoort, Postma, Kappelle, \& de Haan, 2000; Reynolds \& Bigler, 1994). To our knowledge, the Walking Corsi Test (WCT) of Piccardi et al. (2008) is the first visuospatial short-term memory task developed that involves the movement of the person in order to recall sequences of steps that correspond to different spatial locations of the navigational space. This task was designed as a modified version of the Corsi Block-Tapping Test (Corsi, 1972). The WCT has demonstrated that spatial processing is different when the navigational space is considered in the assessment procedure, involving differences in the strategies used and the memory systems engaged (Piccardi et al., 2010; Piccardi, Bianchini et al., 2014; Piccardi, Iaria, Bianchini, Zompanti, \& Guariglia, 2011). More recently, an electronic version of the WCT has supported this finding (Belmonti, Cioni, \& Berthoz, 2015).

The studies conducted with typically developing children clearly showed a delay in the performance of the walking version task compared to the classical one; however, these studies also showed disparity regarding the effect of gender in the performance of children in the new version (Belmonti, et al., 2015; Piccardi, Leonzi, D'Amico, Marano, \& Guariglia, 2014; Piccardi, Palermo et al., 2014). These contradictory results are in line with the inconsistent results concerning gender differences in spatial abilities that can be found in previous published data (for a review see Andreano \& Cahill, 2009; Coluccia \& Louse, 2004; Wang, Cohen, \& Carr, 2014). The literature has focused mainly on young adults and little attention has been paid to the differences in the early ages of development (e.g., Belmonti, et al., 2015; Leon, Cimadevilla, \& Tascon, 2014; Mendez-Lopez, Mendez, Lopez, \& Arias, 2009; Nichelli, Bulgheroni, \& Riva, 2001; Piccardi, Leonzi et al., 2014; Piccardi, Palermo et al, 2014).

Taking into consideration the strong impact of spatial competence on the ability to learn at early ages and bearing in mind the limitations of conventional tasks for the assessment of VSTM (static tasks and artificial stimuli), we propose a novel Augmented Reality (AR) task for the assessment of visuospatial short-term memory called the ARSM task. In another study, the ARSM task obtained high values in perceived satisfaction and usability reported by children (the citation will be included in the final version). The ARSM task involves an active search for a sequence of object images, which are presented in AR and located in the real word. Logie's model considers VSTM to be a storage component that is composed of separate processing parts: the visual cache and the inner scribe (Logie, 1995; 
2003). The visual cache temporarily stores static visual information and the inner scribe deals with spatial and movement information, providing a mechanism whereby visual information can be subjected to rehearsal and transferred to the central executive system. According to Logie's theoretical model of short-term memory, we could argue that performance on the ARSM task requires the children to retain two memory sequences (a sequence of the objects that are visually perceived and a sequence of the spatial locations that the children navigate), whereas the performance on the WCT only involves the sequence for spatial locations since the visual information on the WCT does not vary according to location (Piccardi et al., 2008). Therefore, we considered that the ARSM task provides an opportunity to increase knowledge about the short-term memory ability of children in the navigational space.

There are few studies that focus on visuospatial short-term memory in human development considering real settings during assessment (Belmonti et al., 2015; Piccardi, Leonzi, et al., 2014; Piccardi, Palermo et al., 2014). The present study is aimed at extending our previous investigation about children's performance on the ARSM task (citation included in the final version). Different measures of performance derived from the ARSM task were considered in order to explore the changes throughout development in the VSTM of typically developing children between the ages of 5 and 9 years old. We also aimed to examine gender differences in the ARSM task and to explore the correlation of the children's performance on the ARSM task with their performance on other short-term memory tests for verbal and spatial information for static visual items. In order to determine if full competence in the ARSM task was acquired during the developmental period studied, we compared the performance on this novel task with that obtained in the maturation stage (young adults). Since the ARSM task required retaining information about visual features together with movements between spatial locations, we expected to find a gradual improvement in the visuospatial span with age, continuing after the age of 9 . We did not expect to find gender differences in the overall performance, but a relative advantage for males could arise for some variables related to mastery of the task. Those variables related with a high performance level in the ARSM task would present a strong correlation with performance on static spatial short-term memory tests that require more attention.

\subsection{Participants}

\section{Method}

The participants were 97 children from 5 to 9 years old ( $M$ age $=6.9$ years). There were 55 boys and 42 girls. The parents completed the Parent Report form of The Behavioral Assessment Scale for Children (BASC; Reynolds \& Kamphaus, 1992). We excluded six participants who obtained a score within the clinically significant range according to the BASC for measures of Attention Problems and Hyperactivity (attention problems: three boys; hyperactivity: three boys). The parents also provided information about the development of the children and their medical history. None of the children had visual or hearing impairments or had a breech birth, required neonatal resuscitation, had suffered a brain injury, had a body temperature higher than 40 degrees Celsius in the first five years of life, or were treated with a medication that could potentially impair their cognitive functioning. Three boys aged 5, 7, and 8 years old required oxygen for the first 3-48 hours of life. The children were divided into five groups according to their age. Table 1 summarizes the main characteristics of the final sample, which was composed of 91 children. 
Table 1

Characteristics of the Children

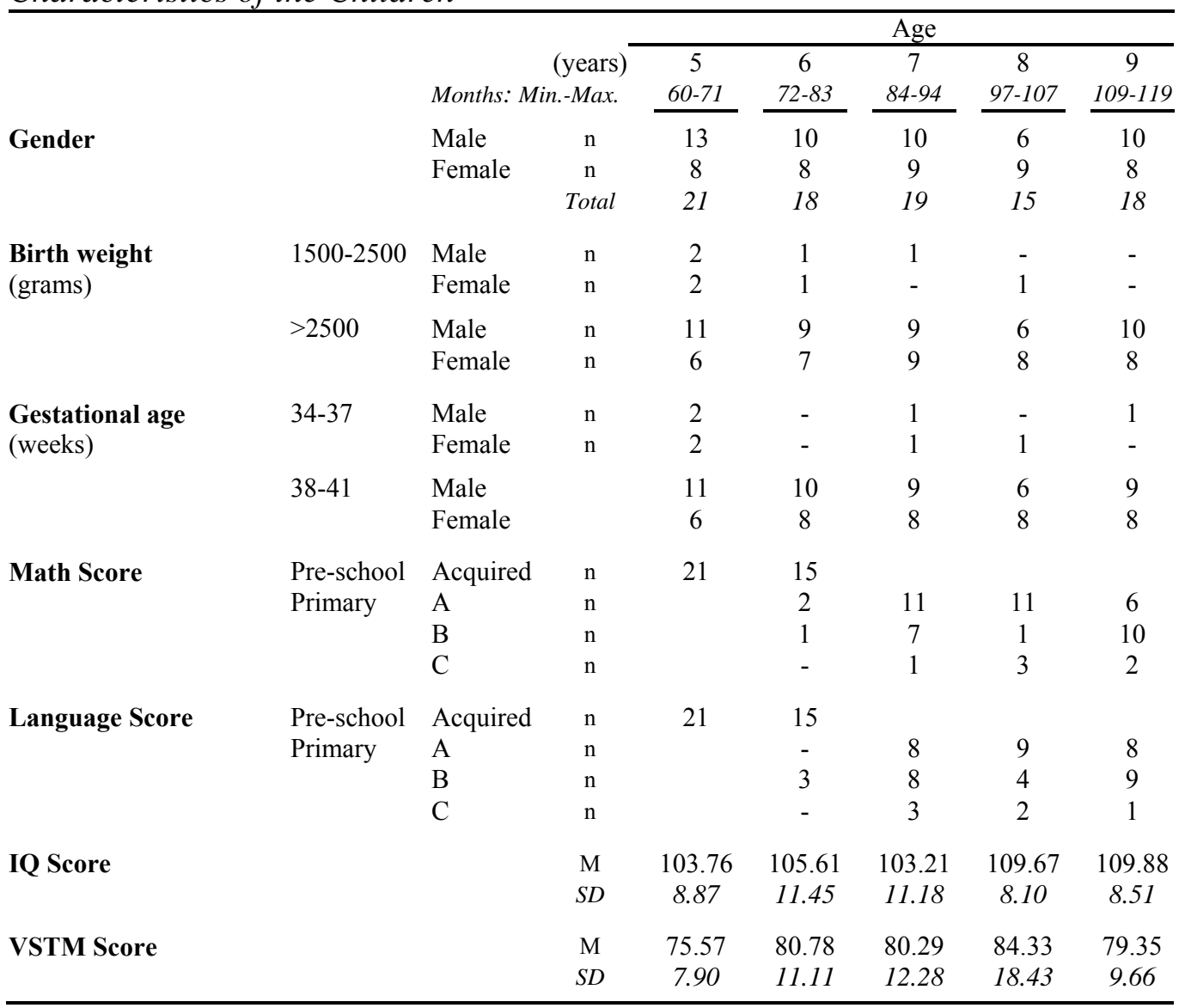

Note. The Language Score and Math Score represent the marks obtained by the participants for the related subject areas reported by parents based on the past school year. $n=$ number of participants; IQ Score = intelligence quotient standardized score obtained using the Reynolds Intellectual Screening Test (Reynolds \& Kamphaus, 2003); $\mathrm{M}=$ mean; $S D=$ standard deviation; VSTM Score = visuospatial short-term memory standardized score estimated using the Dot Matrix subtest of the Automated Working Memory Assessment (Alloway, 2012).

There were 15 additional adult participants (eight men and seven women, ranging in age from 25 to 30 years old, $M$ age $=26.6$ years old) who were included to obtain performance measures in the ARSM task in adulthood. This age range was selected after informal observations indicating that full competence to perform the task was guaranteed at these ages. This group was composed of postgraduate students who provided some information about their medical history, driving habits, and medication that could potentially affect their cognitive performance. The adult participants did not have a previous history of head injury, neurological disorders, or psychiatric disorders. They did not regularly consume cannabis or other illicit drugs. Table 2 summarizes information about the adult sample. 
Table 2

Characteristics of the Adults

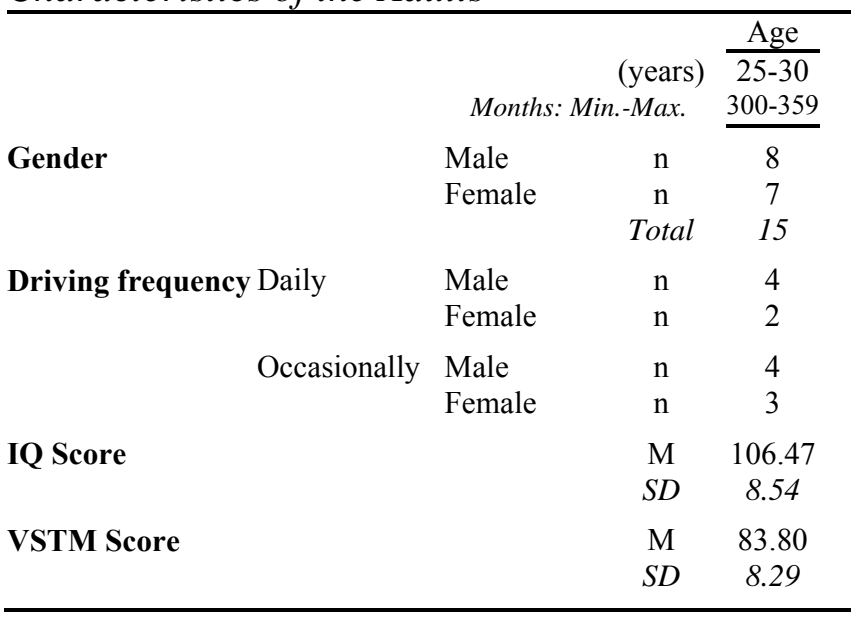

Note. The frequency of driving refers to the last couple of years. $\mathrm{n}=$ number of participants; IQ Score = intelligence quotient standardized score obtained using the Reynolds Intellectual Screening Test (Reynolds \& Kamphaus, 2003); $\mathrm{M}=$ mean; SD = standard deviation; VSTM Score $=$ visuospatial short-term memory standardized score estimated using the Dot Matrix subtest of the Automated Working Memory Assessment (Alloway, 2012).

The study was conducted in accordance with the European Directive 2001/20/EC and the Helsinki Declaration for biomedical research involving humans. The parents of the participating children received written information about the aims and procedures of the study and they signed a consent form to allow their children to participate in it. The adult participants also completed a written informed consent form. The children who participated received a small reward consisting of a diploma right after the test sessions, whereas the adults received a reward of five euros. The participants were fully free to leave the study at any time and they were not informed about the reward until the end of the study. The research protocol was approved by the University Ethics Committee.

Given that research suggests a close relation between spatial short-term memory and intelligence (e.g., Ackerman, Beier, \& Boyle, 2005; Giofrè, Mammarella, \& Cornoldi, 2013), we administered two tests to discard any differences among the groups in their level of general intelligence and VSTM ability. We calculated the intelligence quotient (IQ) standardized score of the sample using the Reynolds Intellectual Screening Test (RIST; Reynolds \& Kamphaus, 2003). The specific constructs that we controlled using the RIST were: verbal reasoning taking into account vocabulary level, general information, and language development; and non verbal reasoning, using a subtest that also involves the use of spatial ability, visual representation and other non-verbal capacities. This subtest involves questions of reverse non-verbal analogy. The VSTM ability was estimated according to the standardized score of the Dot Matrix subtest of the Automated Working Memory Assessment (AWMA-2; Alloway, 2012). We could not administer the Dot Matrix subtest to six of the participants due to problems with the AWMA-2's server during the testing phase. These missing values correspond to: one boy and one girl from the 7-year-old group, two boys and one girl from the 8-year-old group, and one girl from the 9-year-old group. Table 1 shows these scores for each group of children and Table 2 shows the scores for the group of 2530 -year-olds. There were no differences among the groups according to their general intelligence (IQ score range: $80-122 ; F(5,100)=1.57, p=.17$ ). Also, there were no 
differences among groups in their VSTM ability (Dot Matrix score range: $65-120 ; F(5,94)=$ $1.36, p=.24)$.

\subsection{Tasks and Procedure}

2.2.1. Augmented Reality Visuospatial Short-Term Memory Task. All the participants of the study performed the ARSM task (the citation will be included in the final version). The ARSM task consists of a visuospatial memory span test in which the visual items are shown on a tablet screen when the tablet camera focuses on a specific spatial location. The spatial locations are boxes that are strategically located in the testing area. The starting position of the children is the center of the testing area. We placed a yellow square on the floor indicating the starting position (see Figure 1). The task involves showing the selected virtual objects in a real location and have the participant try to remember where the objects were in the same sequence. The number of objects to be retained increases throughout the task depending on the performance in previous trials. The task has different levels that differ in the number of locations and the objects used in each trial. There are six different levels (see Figure 2). Each level contains a maximum of seven trials. Each trial consists of two phases. In the first phase, the participant has to search for the objects by walking from the starting position to a particular box/location pointed to by the examiner. Then, the participant opens and focuses on the box with the camera of the tablet, and the screen shows the object for five seconds. In the second phase, the tablet screen shows an object and the participant has to remember the location where the object was (successes and failures are recorded). In this phase, the participant has to walk from the starting position to the location and then open the box and point the camera of the Tablet in order to register the response. The chances for completing a specific level are determined by the number of successes and / or failures. If there are three consecutive successful trials for a number of trials less than or equal to seven, a level ends successfully. A participant performs the next level if he/she successfully passes the previous one. The objects to be found in each trial are equal to the level of difficulty (Level 1 - Level 6), and the number of spatial locations is the level $\times 2$ (e.g., in Level 1, there are two locations and only one object to be recalled in each trial; in Level 4, there are eight locations and four objects to be found in each trial). To explain the process, the steps that are followed in the initial level (Level 1) are the following: in the first trial, the object appears over the spatial location A (Figure 2, see box A within Level 1). At this moment, the child can open either of two boxes looking for an object (the boxes are named A and B). The person in charge tells the child which box to look in. An object (a watch) appears over A. The child has to go to the starting position. The ARSM task asks the child to find the box where the watch was. If the child goes to A, the system registers a success. If the child goes to $\mathrm{B}$, the system registers a failure. In the second trial, the object (a comb) appears over B. The procedure is exactly the same as the first trial. If the child goes to $\mathrm{B}$, the system registers a success, otherwise a failure is registered. In the remaining trials, the objects appears over B, A, A, B, and A, respectively. After the third trial, if the number of consecutive successful trials is three, the child goes to the next Level (Level 2, two objects to be recalled in each trial). If the fifth trial is reached and a failure is registered, Level 1 ends unsuccessfully because it is not possible to have three more successful trials (only two could be achieved). 
Figure 1.

Child performing the ARSM task and view of Level 3. Note that an examiner accompanies the participant during the assessment session.

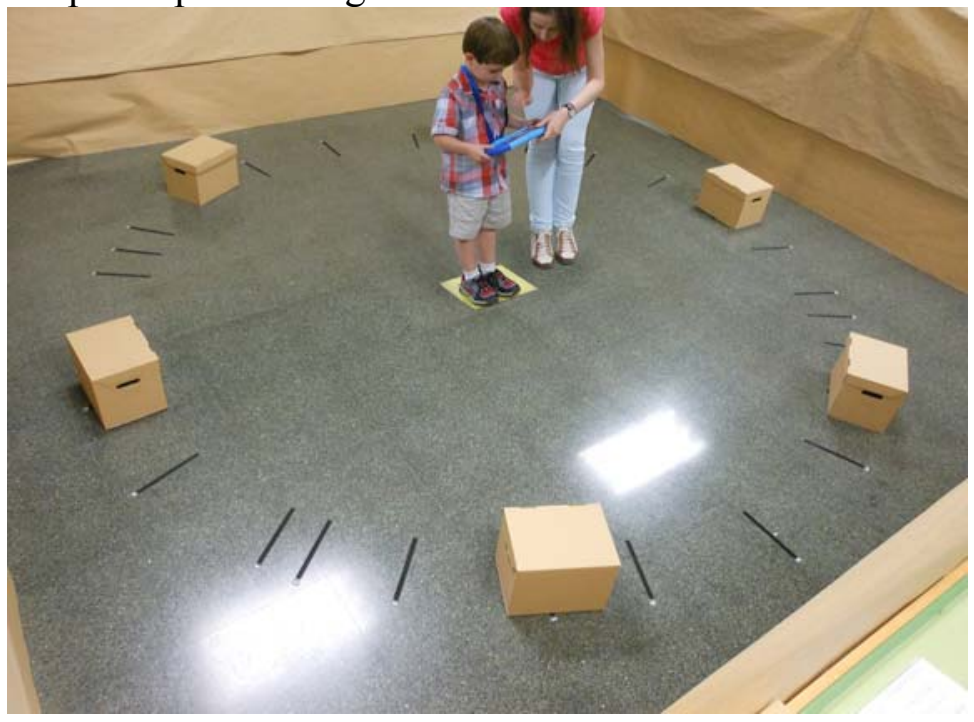

Even though the ARSM task includes a guide character to help the children focus on the task, an examiner accompanies the participant during the task and points to the spatial locations that should be visited at any given time. To allow the participants to get acquainted with the system, a habituation trial that is similar to a trial of Level 1 is performed in a different scenario just prior to conducting the task. A more detailed explanation about the technical and procedural aspects of the ARSM task can be found in (the citation will be included in the final version).

Figure 2.

Schematic representation of the different levels of the ARSM task.
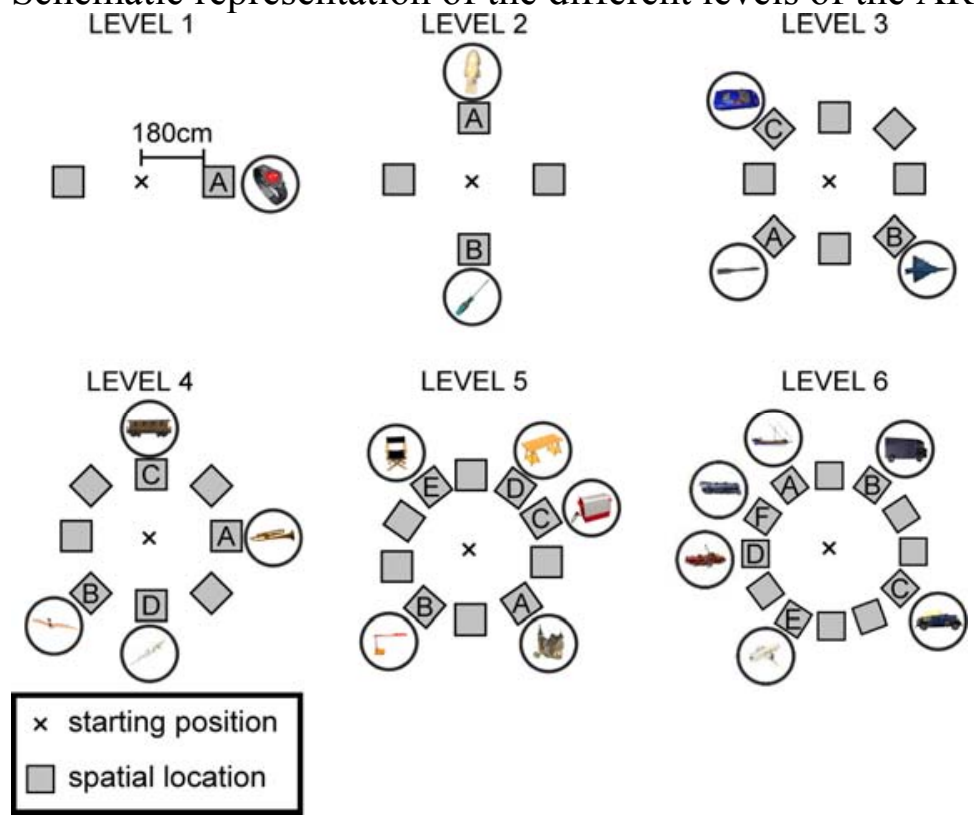

2.2.2. Traditional Memory Tasks. Visuospatial memory and verbal memory were also assessed in the groups of children using traditional paper and pencil tasks. We selected specific subtests that are included in the Test of Memory and Learning battery (TOMAL; 
Reynolds \& Bigler, 1994). The TOMAL battery assesses various domains of memory in children and adolescents ranging in age from 5 years old to 19 years old.

For the assessment of VSTM, we selected three TOMAL subtests: Memory for Location (ML); Visual Sequential Memory (VSM); and Visual Selective Reminding (VSR). These subtests assess the ability of retrieval of visuospatial items printed on paper immediately upon stimulus presentation. The ML subtest consists of a spatial recall task of one or more large black dots that appear within a square or rectangle. The child is asked to identify the location of the dots within a grid. The range of the grid is $3 \times 3$ and $4 \times 4$ (with 9 locations and 16 locations, respectively). The VSM subtest assesses the ability to recall a set of two to seven abstract designs sequentially. Finally, the VSR subtest consists of a pointing task in which children point to specified dots on a card, following a demonstration by the examiner. The child is reminded of items recalled incorrectly. Trials continue until perfect performance is achieved or until eight trials have been attempted. The child's performance on a delayed visuospatial recall task was also taken into account. The Visual Selective Reminding Delayed (VSRD) subtest of the TOMAL was used. This task assesses the ability to recall the dots learned in the VSR task with a delay of 20 minutes.

Finally, in order to assess immediate retrieval of non-spatial items, we used two verbal span subtests of the TOMAL battery: Digits Forward and Digits Backward. The Digits Forward is a number recall task that measures low-level rote recall of a sequence of numbers. The Digits Backward task (a variation of the Digits Forward task) consists of a recall of a sequence of numbers but in reverse order.

2.2.3. Procedure. The participants were tested individually in two sessions of approximately 45 minutes each, which generally took place on the same day and between 9:00 A.M. and 6:00 P.M. There was an inter-session interval break of 15 minutes. The participants were randomly assigned to one of the following experimental conditions: Condition I and Condition II. In Condition I, the participants were assessed with the ARSM task and were then evaluated with neuropsychological tests. In Condition II, the participants were evaluated with neuropsychological tests and were then assessed with the ARSM task.

Each participant completed the neuropsychological tests individually in one of two settled sequences. In one of the sequences, the participants completed the RIST (Reynolds \& Kamphaus, 2003). Afterwards, they completed the selected subtests included in the battery TOMAL (Reynolds \& Bigler, 1994) and the Dot Matrix subtest of the AWMA-2 (Alloway, 2012). In the other sequence, they completed the Dot Matrix subtest and then they performed the RIST and the selected subtests of the TOMAL. The selected subtests of the TOMAL were administered in the following order: VSR, Digits Forward, VSM, ML, Digits Backward, and VSRD. The group of 25-30-year-olds was assessed following the same experimental conditions except for the TOMAL subtests, which were not administered.

\subsection{Dependent Variables}

We considered six variables that are related to performance in the ARSM task: visuospatial span, score, percentage of trials completed, approximation errors (adjacent), nonapproximation errors (far); and percentage of accurate performance. The visuospatial span involved the number of the highest level that a participant could successfully complete. As a memory span measure, this variable represented the capacity of the short-term storage to retain visuospatial items. For the score variable, we calculated the sum of the number of trials that were correctly performed of all of the levels done. Since this variable represented a measure of the general performance, the system of scoring awarded participants with perfect execution within each level. Hence, a score of seven points was given to those levels in which the first three trials were performed correctly; for the remaining levels, one point was 
given for each correct trial performed. The percentage of trials completed variable was calculated taking into account the number of trials successfully completed of the total trials performed. The variable was associated with the overall effectiveness to solve the task, indicating the performance accuracy. The approximation errors variable was the sum of the number of errors committed by pointing to a spatial location that was placed adjacent to the target location. This variable allowed us to differentiate the participants with a certain degree of memory for a spatial sequence composed of 3 to 5 elements from those who had completely lost the sequence (did not remember any elements). The non-approximation errors variable was the total number of errors committed during the task by pointing to a spatial location that was placed far from the target location. It was assumed that participants with poor spatial orientation were less accurate in locating the objects that were asked for. We considered the levels of highest difficulty that were achieved by the children (Level 3, Level 4, and Level 5) for calculations in the percentage of accurate performance and approximation errors variables. The percentage of accurate performance variable was calculated taking into account the number of correct responses performed within the first three trials of the task. This level-dependent variable indicated the performance in relation to accuracy trials with a longer list of spatial items.

With regard to the traditional assessment approaches, we took into account the direct scores of the VSM, VSR, and VSRD subtests of the TOMAL as performance indicators. In the case of the ML subtest, we took into account the sum of the number of correctly recalled dots, except for the dots related to items in which the array of dots is aligned. Thus, we excluded dots of items 1, 13, 25, and 26 from the sum. For the measures of the ability of retrieval of non-spatial items, we used the digit span score obtained in the forward condition (Digits Forward) and in the backward condition (Digits Backward).

\subsection{Statistical Analyses}

All the variables of the study were analyzed using a two-way ANOVA for independent measures (Group $\times$ Gender). The Group variable corresponded to the division of the sample made according to the age of the participant (see Table 1 and Table 2). This led to the following groups: the 5-year-old group, the 6-year-old group, the 7-year-old group, the 8year-old group, the 9-year-old group and the 25-30-year-old group. Levene's test was applied to check the assumption of homogeneity variance for independent measures. For the post hoc analysis, if the assumption of homogeneity was met $(p>.05)$, we applied the Bonferroni post hoc test; otherwise $(p<.05)$, we applied the Games-Howell test.

We also calculated Pearson's correlations between measures of overall performance on the ARSM task (visuospatial span, score, percentage of trials completed, and nonapproximation errors) and performance scores on the TOMAL subtests controlling for age. We performed the same analyses taking into account the percentage of accurate performance and the number of approximation errors in Level 4 of the task and the measures obtained on the TOMAL subtests. We only considered the measures in Level 4 for these analyses because it was the most difficult level that covered a relatively large sample of age groups.

All of the analyses were done using IBM SPSS Statistics, version 19.0. The results were considered to be statistically significant if $p<.05$.

\section{Results}

\subsection{Augmented Reality Visuospatial Short-Term Memory Task}

3.1.1. Visuospatial span. For the visuospatial span reached in the ARSM task, the analysis of the number of levels of the ARSM task completed with ANOVA (Group $\times$ Gender) revealed significant effects of the Group factor, $F(5,94)=49.26, p<.0001, \eta_{\mathrm{p}}{ }^{2}=$ 0.72 , but not for the Gender factor, $F(1,94)=1.39, p=.24$, or for the interaction between 
Group and Gender factors, $F(5,94)=2.30, p=.051$. The variances were not homogeneous ( $p$ $<.0001)$. The group of adult participants $(25$ - to 30-year-olds) completed more levels of the task than the groups of children $(5-6-7-8-9$-year-olds; see Table 3$)(p<.0001)$. The groups of 8 and 9-year-olds were also better in this measure of performance than the 6 and 5-year-old groups $(p<.007)$. The group of 9-year-olds also obtained a higher span than the group of 7year-olds $(p=.001$; see Table 3$)$.

3.1.2. ARSM task score. To find out if there were differences in overall performance on the ARSM task, we calculated this score (see Table 3 ). An ANOVA (Group $\times$ Gender) disclosed differences for the Group factor, $F(5,94)=18.23, p<.0001, \eta_{\mathrm{p}}{ }^{2}=0.49$, but not for the Gender factor, $F(1,94)=1.60, p=.21$, or for interaction between Group and Gender, $F(5,94)=1.17, p=.33$. The variances were not homogeneous $(p=.006)$. The post hoc analysis of the Group factor showed that the group of 5 and 6-year-olds had a lower score than the 7, 8, and 9-year-old groups $(p<.007)$ and the 25-30-year-old group $(p=.02)$. The group of 7-year-olds also obtained a lower score than the group of 9-year-olds $(p=.001)$.

3.1.3. Percentage of trials completed successfully. Similarly, the analysis of the percentage of trials completed successfully with ANOVA (Group $\times$ Gender) revealed significant effects for the Group factor, $F(5,94)=14.53, p<.0001, \eta_{\mathrm{p}}^{2}=0.44$, but not for the Gender factor, $F(1,94)=3.64, p=.06$, or for the interaction between Group and Gender, $F(5,94)=.843, p=.52$. Levene's test indicated that the variances were not homogeneous ( $p$ $=.009)$. The post hoc analysis of the group variable showed that the $25-30$-year-old group completed more trials successfully than the groups of children of all ages studied $(5,6,7,8$, and 9-year-old groups). Also, the 8 and 9-year-old groups had a higher percentage of trials performed successfully than the 5-year-old group $(p<.02$; see Table 3$)$.

3.1.4. Non-approximation errors. The analysis of the number of non-approximation errors disclosed no differences for the Gender factor, $F(1,94)=3.51, p=.06$, but differences for the Group factor, $F(5,94)=2.81, p=.021, \eta_{\mathrm{p}}{ }^{2}=0.13$, and for the interaction between Group and Gender, $F(5,94)=2.90, p=.02, \eta_{\mathrm{p}}{ }^{2}=0.13$. The variances were not homogeneous $(p=.006)$. The post-hoc analysis of the group variable showed that the girls in the 7-year-old group performed worse than the boys $(p=.008)$. We also found a similar significant difference in the 25-30-year-old group $(p=.01)$.

3.1.5. Percentage of successful responses performed within the first three trials of the task. To determine if there were differences in the ability to complete each level of the ARSM task accurately, we examined the percentage of successful responses performed within the first three trials of the task within the levels with the highest difficulty (Level 3, Level 4, and Level 5; see Table 3).

For Level 3, an ANOVA disclosed significant differences for the Group factor, $F(5$, $85)=18.57, p<.0001, \eta_{\mathrm{p}}{ }^{2}=0.52$, but not for the Gender factor, $F(1,85)=.01$, ns, or for the interaction between Group and Gender $F(5,85)=.70$, ns. The variances were homogeneous $(p=.52)$. The post hoc analysis of the group variable showed that the 5, 6, and 7-year-old groups were less accurate in the performance in Level 3 than the 9-year-old group and the 25 -30-year-old group $(p<.0001)$. Similarly, the 5 and 6 -year-old groups performed worse than the 8-year-old group $(p<.003)$.

No child in the 5 and 6-year-old groups performed Level 4. An ANOVA (Group $\times$ Gender) revealed significant effects for the Group factor, $F(3,42)=7.90, p<.0001, \eta_{\mathrm{p}}^{2}=$ 0.36 , and the gender variable, $F(1,42)=5.23, p=.03, \eta_{\mathrm{p}}{ }^{2}=0.11$, but not for the interaction between Group and Gender $F(3,42)=1.38$, ns. The variances were homogeneous $(p=.19)$. 
The Post hoc analysis revealed that the 25-30-year-old group had better performance in Level 4 than the remaining groups of children that performed this level $(p<.005)$. Although the effect size of the gender variable was medium, this measure of accuracy within Level 4 was higher in the case of the males that reached this level (Male: $M=65.28, S D=31.82$; Female: $M=47.44, S D=35.49$ ).

Finally, Level 5 of the ARSM task was performed by some of the participants of the 8 and 9-year-old group and the 25-30-year-old group. An ANOVA (Group $\times$ Gender) did not find differences for the Group factor, $F(2,17)=1.65$, ns, or the Gender factor, $F(1,17)=.04$, ns.

3.1.6. Approximation errors. We examined if there were differences in the number of error responses related to a spatial location that was adjacent to a target at the highest levels of difficulty of the task (see Table 3 ). Thus, an ANOVA (Group $\times$ Gender) was performed for Level 3, Level 4, and Level 5.

In Level 3, the number of approximation errors was different between groups, $F(5$, $85)=8.10, p<.0001, \eta_{\mathrm{p}}{ }^{2}=0.32$. No effects were found for gender: $F(1,85)=.69$, ns.or interaction: $F(5,85)=.41, n s$.). The variances were not homogeneous $(p=.001)$. The post hoc test showed that the 5 and 6-year-old groups had more errors compared to the 8 and 9year-old groups and the 25-30-year-old group $(p<.05)$. Also, the 7-year-old group committed more errors than the 25-30-year-old group $(p=.005)$.

In relation to Level 4 , the ANOVA (Group $\times$ Gender) disclosed significant differences between groups, $F(3,42)=7.98, p<.0001, \eta_{\mathrm{p}}{ }^{2}=0.36$, and gender, $F(1,42)=$ $4.40, p=.042, \eta_{\mathrm{p}}^{2}=0.09$. No effect of interaction was found, $F(3,42)=2.02, p=.12$. The variances were homogeneous $(p=.07)$. The post hoc test showed that the 7-year-old group committed more errors than the 8-year-old group and the 25-30-year-old group $(p<.003)$. Also, the 9-year-old group performed more errors than the 25-30-year-old group $(p=.01)$. In addition, the females had more errors than the males on the ARSM task within Level 4 (Male: $M=.62, S D=.82$; Female: $M=1, S D=1.13$ ), but the effect size of the gender variable was low.

For Level 5, there were no significant differences between the groups for either gender (Group: $F(2,16)=1.21, n s$.; Gender: $F(1,16)=2.03$, ns.) or Interaction: $F(2,16)=$ $.50, n s$.

\subsection{Traditional Memory Tasks}

3.2.1. Visuospatial short-term memory. An ANOVA (Group $\times$ Gender) was performed for the measures in the ML, VSM, and VSR subtests (see Table 4). In the ML subtest, there were significant effects for the group variable, $F(4,81)=28.42, p<.0001, \eta_{\mathrm{p}}{ }^{2}$ $=0.58$, but no significant gender effect or interaction effect (Gender: $F(1,81)=3.41, p=.07$; Interaction: $F(4,81)=1.02, n s$. $)$. The variances were not homogeneous $(p<.0001)$. The post hoc test showed that the 8 and 9-year-old groups recalled a higher number of spatial items than the 5, 6, and 7-year-old groups $(p<.02)$. For performance on the VSM subtest, the ANOVA disclosed the same pattern of significant effects. There were differences between groups, $F(4,81)=17.20, p<.0001, \eta_{\mathrm{p}}^{2}=0.46$, but no gender effect, $F(1,81)=.93, p=.34$, or interaction effect, $F(4,81)=.46, n s$. The variances were homogeneous $(p<.09)$. The post hoc test showed that the 9-year-old group performed better on the VSM subtest than the other age groups of children of the study $(5,6,7$, and 8 -year-olds; $p<.0001)$.

For the VSR subtest, an ANOVA revealed a significant effect for group, $F(4,81)=$ $5.20, p=.001, \eta_{\mathrm{p}}{ }^{2}=0.20$. There were no significant effects for gender or interaction (Gender: $F(1,81)=3.10, n s$; Interaction: $F(4,81)=1.96, n s$. $)$. The variances were not homogeneous $(p=.002)$. The post hoc test showed that the 8 and 9 -year-old groups recalled a higher 
number of elements on this subtest than the 6-year-old group $(p \leq .049)$. The 8-year-old group also performed better on this task than the 5-year-old group $(p=.01)$.

3.2.2. Delayed visuospatial memory. An analysis of the number of elements recalled on the VSRD subtest with an ANOVA (Group $\times$ Gender) revealed a significant effect for the Group factor, $F(4,81)=3.08, p=.02, \eta_{\mathrm{p}}{ }^{2}=0.13$, and Gender factor, $F(1,81)=5.08, p=.03$, $\eta_{\mathrm{p}}{ }^{2}=0.06$, but no interaction between Group and Gender $F(4,81)=.38$, ns. However, the effect size of the Group factor and gender was low. The females showed a better delayed recall than the males (Male: $M=4.71, S D=1.50$; Female: $M=5.45, S D=1.31$; see Table 4). The variances were homogeneous $(p<.23)$. The post hoc analysis showed that the 9-year-old group had a better performance than the 5-year-old group $(p=.04)$.

3.2.3. Verbal span. An ANOVA (Group $\times$ Gender) disclosed a significant effect for the Group factor for both span measures, Digits Forward and Digits Backward subtests (forward: $F(4,81)=11.76, p<.0001, \eta_{\mathrm{p}}{ }^{2}=0.37$; backward: $F(4,81)=6.94, p<.0001, \eta_{\mathrm{p}}{ }^{2}=$ 0.25 ; see Table 4). There were no significant effects for the Gender factor (forward: $F(1,81)$ $=.32, p=.57$; backward: $F(1,81)=.84, p=.36)$ or interaction between Group and Gender (forward: $F(4,81)=.54, p=.71$; backward: $F(4,81)=.18, p=.95)$. In the measures of the Digits Forward subtest, the variances were not homogeneous $(p=.02)$. The post hoc analysis showed a higher forward digit span recall in the 9-year-old group than the 5,6, and 7-yearold groups $(p \leq .28)$. Also, the 7 and 8 -year-old groups had a better recall in the Digit Forward subtest than the 5 -year-old group $(p \leq .01)$. In relation to the backward digit span recall, the variances were homogeneous $(p=.09)$ and the post hoc analysis revealed that the number of digits recalled was higher in the 7, 8, and 9-year-old groups than in the 5 and 6year-old groups $(p<.02)$.

Table 4

Mean Scores and Standard Deviations for Traditional Memory Tasks

\begin{tabular}{lcccccccccccc}
\hline & Group & $5 \mathrm{YM}$ & $5 \mathrm{YF}$ & $6 \mathrm{YM}$ & $6 \mathrm{YF}$ & $7 \mathrm{YM}$ & $7 \mathrm{YF}$ & $8 \mathrm{YM}$ & $8 \mathrm{YF}$ & $9 \mathrm{YM}$ & $9 \mathrm{YF}$ \\
\hline & $\mathrm{n}$ & 13 & 8 & 10 & 8 & 10 & 9 & 6 & 9 & 10 & 8 \\
ML & $\mathrm{M}$ & 11.54 & 10.50 & 17.40 & 15.25 & 23.50 & 24.22 & $\mathbf{6 5 . 1 7}$ & $\mathbf{4 4 . 2 2} * * * \mathbf{8 3 . 3 0}$ & $\mathbf{6 4 . 3 8} * * *$ \\
& $\mathrm{SD}$ & 10.94 & 7.21 & 15.63 & 13.34 & 13.57 & 21.57 & 38.59 & 17.15 & 36.94 & 25.55 \\
VSM & $\mathrm{M}$ & 12.23 & 17.13 & 15.20 & 15.38 & 18.60 & 20.33 & 19.67 & 19.56 & $\mathbf{3 0 . 8 0}$ & $\mathbf{3 1 . 0 0} * * * *$ \\
& $\mathrm{SD}$ & 5.62 & 4.55 & 3.46 & 6.80 & 3.75 & 3.57 & 5.05 & 10.58 & 10.51 & 7.75 \\
VSR & $\mathrm{M}$ & 37.62 & 34.00 & 32.50 & 36.25 & 35.40 & 42.56 & $\mathbf{4 3 . 6 7}$ & $\mathbf{4 2 . 5 6} * \#$ & $\mathbf{4 0 . 3 0}$ & $\mathbf{5 0 . 1 3}$ \\
& $\mathrm{SD}$ & 9.27 & 5.66 & 9.34 & 10.65 & 8.81 & 4.56 & 3.83 & 4.19 & 12.19 & 9.34 \\
VSRD & $\mathrm{M}$ & 4.38 & 4.75 & 4.30 & 4.88 & 4.60 & 5.56 & 5.33 & 5.66 & $\mathbf{5 . 3 0}$ & $\mathbf{6 . 5 0} * *$ \\
& $\mathrm{SD}$ & 1.32 & 1.16 & 1.64 & 1.55 & 1.65 & 1.01 & 0.52 & 1.13 & 1.77 & 1.19 \\
Digit span (forward) & $\mathrm{M}$ & 4.08 & 4.25 & 4.30 & 4.25 & $\mathbf{4 . 9 0}$ & $\mathbf{4 . 5 6} *$ & $\mathbf{5 . 1 7}$ & $\mathbf{4 . 8 9} *$ & $\mathbf{5 . 4 0}$ & $\mathbf{5 . 5 0} * * *$ \\
& $\mathrm{SD}$ & 0.28 & 0.46 & 0.82 & 0.46 & 0.32 & 0.73 & 0.98 & 0.78 & 0.52 & 1.07 \\
Digit span (backward) & $\mathrm{M}$ & 2.92 & 3.25 & 3.00 & 3.13 & $\mathbf{3 . 7 0}$ & $\mathbf{3 . 8 9} * *$ & $\mathbf{3 . 8 3}$ & $\mathbf{3 . 8 9} * *$ & $\mathbf{3 . 9 0}$ & $\mathbf{3 . 8 8} * *$
\end{tabular}

Note. The groups are divided by both age and gender. $5 \mathrm{YM}=5$-year-old male group; $5 \mathrm{YF}=$ 5-year-old female group; 6YM =6-year-old male group; 6YF =6-year-old female group; 7YM = 7-year-old male group; 7YF = 7-year-old female group; 8YM = 8-year-old male group; 8YF = 8-year-old female group; 9YM = 9-year-old male group; 9YF = 9-year-old female group; $\mathrm{ML}=$ Memory for Location; VSM = Visual Sequential Memory; VSR = Visual Selective Reminding; VSRD $=$ Visual Selective Reminding Delayed; $\mathrm{n}=$ number of participants; $\mathrm{M}=$ mean; $S D=$ standard deviation. 
Symbols for group effects: $\left({ }^{* * * *}\right)$ Significantly higher as compared to 5, 6, 7 and 8-year-old groups; $\left(^{* * *}\right)$ significantly higher as compared to 5,6 , and 7 -year-old groups; $\left({ }^{* *}\right)$ significantly higher as compared to 5 and 6 -year-old groups; $\left({ }^{*}\right)$ significantly higher as compared to the 5year-old group; $\left(^{\#}\right)$ significantly higher as compared to the 6-year-old group.

$\left.{ }^{\&}\right)$ Main effect of gender.

\subsection{Correlations between ARSM Task and Traditional Tasks}

Pearson correlations controlling for age are shown in Table 5. The performance score of the ARSM task significantly correlated with the measure of the ML subtest $(r=.32 ; p<$ $.005)$, the VSM subtest $(r=.23 ; p=.03)$, and the VSRD subtest $(r=.25 ; p<.02)$. The measure of visuospatial span also significantly correlated with the ML subtest $(r=.27 ; p<$ $.01)$ and the VSM subtest $(r=.24 ; p=.02)$. Moreover, the measures of performance on the ARSM task showed positive correlations among them. We found that the score significantly correlated with the visuospatial span $(r=.84 ; p<.0001)$, the percentage of trials completed $(r=.50 ; p<.0001)$, and the percentage of successful responses performed within the first three trials of Level $4(r=.71 ; p<.0001)$. The percentage of successful responses performed within the first three trials of Level 4 was also significantly correlated with the percentage of trials completed $(r=.55 ; p=.001)$ and the visuospatial span $(r=.36 ; p=.03)$. In addition, the total number of non-approximation errors showed a negative correlation with the percentage of trials completed $(r=-.78 ; p<.001)$.

Similarly, the scores on some TOMAL subtests showed positive correlations among them. We found that the performance on the ML subtest was significantly correlated with the performance on the VSM subtest $(r=.31 ; p<.01)$, the VSR subtest $(r=.29 ; p<.01)$, and the Digit Forward subtest $(r=.23 ; p=.03)$. Also, the measure obtained in the VSM subtest significantly correlated with the scores of the VSRD subtest $(r=.34 ; p=.001)$ and the Digit Forward subtest $(r=.33 ; p<.01)$. Finally, the score on the VSR subtest significantly correlated with the score on its delayed version (VSRD: $r=.63 ; p<.001$ ).

We found significant correlations between measures of accuracy and approximation errors committed in Level 4 of the ARSM task and the performance scores on the TOMAL subtest. The measure of performance accuracy within Level 4 showed positive correlation with the measure of performance in the ML subtest $(r=.36 ; p=.04)$. In addition, the number of approximation errors significantly correlated with the performance on the Digit Span Backward subtest $(r=.45 ; p<.01)$.

\section{Discussion}

The results of this study showed that the visuospatial span for items presented in the extrapersonal space improved in children at different stages of child development using the ARSM task. Interestingly, the most significant increase in the number of visuospatial items recalled occurred when the children reached the age of 8 years old. Despite the significant increase in the number of visuospatial items recalled by the 8-9-year-olds, the maturation of the visuospatial span was not yet completed. The maximum performance corresponded to a range of about 3.96-5.84 visuospatial items recalled by the young adults. The adult's values indicated an advantage of a range of about 1.59-1.89 items over the values of the 8-9-yearolds. In addition, the VSTM span in our navigational task was not influenced by gender, but there was a slight advantage for males when the difficulty of the task increased regarding the performance accuracy and the errors committed, with a small effect size. Similarly, the shortterm memory load was not affected by gender in the static span tests for verbal and spatial items. With regard to correlations, the performance on the ARSM task correlated with spatial short-term memory tasks for static items presented simultaneously and sequentially. 
We observed an increase in the number of items recalled in the ARSM task with age, even when there was no statistical significance for some age groups. This improvement with age is similar to that found in studies that tested children in a similar age range with other span tasks for spatial items presented in peripersonal space (e.g., Corsi Block Tapping Test; Isaacs \& Vargha-Khadem, 1989; Leon et al., 2014; Nichelli et al., 2001; Piccardi, Leonzi et al., 2014; Piccardi, Palermo et al., 2014) and navigational space (e.g., WCT; Piccardi, Leonzi et al., 2014; Piccardi, Palermo et al., 2014). It should be noted that the main improvement in the mean span value was at 8 years old (an increase of 0.73 items in relation to the 7 -year-old group) and the difference between the number of items recalled between 8-year-olds and 9year-olds was small (increase of 0.22 items). In support of this observation, this profile of improvement was also found in the performance on the WCT navigational span task (Piccardi, Palermo et al., 2014). In addition, Gathercole (1999) described a more gradual improvement in short-term memory after 8 years of age in a review of data obtained in span tasks for several types of information. This review also described that performance reaches the asymptotic level after the age of 11 years old. Taken together, these observations might support theoretical frameworks of growth cycles in cognitive development, which conceive that the mastery of the skill does not change as a linear function of age but rather undergoes a pattern characterized by discontinuities (Case, 1992; Fischer \& Rose, 1996).

The ARSM task span was smaller in the youngest age groups $(5,6$, and 7-year-olds) when compared with the performance on the WCT (Piccardi, Palermo et al., 2014). We might consider that the ARSM task is more difficult to perform and that the VSTM requirements needed to complete this task are not fully acquired at these ages. Specifically, the ARSM task demands coordination between the visual information seen in the real world and the visual information seen on the tablet. Hence, we suggest that more visual features might be retained in the ARSM task than in the WCT, increasing the time-related decline in memory in the 57-year-olds. The difficulty of the youngest groups to retain the visuospatial information of the ARSM task is supported in the study by Logie and Pearson (1997). They studied short-term memory in the developmental period between 5 to 12 years of age and found that performance had greater differences across development when visual processing was involved compared with spatial processing. In addition, based on the data we collected from the young adults, it seems that the maximum performance on the ARSM task is also lower than the maximum performance registered in the navigational task of Piccardi et al. (2008). This observation could also support the greater complexity of the ARSM task.

An alternative explanation for the difficulty of the youngest age groups to remember more than two visuospatial locations could be related to the development of verbal ability. Verbal-based strategies might support the encoding of two types of information: the boxes explored and the characteristics of the objects presented. The association between objects and spatial locations was demonstrated to be more influenced by verbal skills over the years (Cowan, Saults, \& Morey, 2006).

From a neuroanatomical perspective, the maturation of brain structures underlying short-term memory and attention could explain the improvement in the performance of the ARSM task with age. Thus, the frontal and parietal cortical areas were involved in VSTM tasks for stimuli presented on a screen (Klingberg, Forssberg, \& Westerberg, 2002; Kwon, Reiss, $\&$ Menon, 2002). The activation of these areas and the changes in their connectivity were linked to the improvement of performance with age, and the maturation of their function was reached after adolescence (Nagy, Westerberg, \& Klingberg, 2004; Zald \& Iacono, 1998). Apart from these findings, we should also consider the specific characteristics of a navigational task when discussing this issue. Nemmi et al. (2013) have found a neural circuit that is specifically involved in the performance of spatial memory tasks for sequences of locations in the extrapersonal space which entails the dorsolateral prefrontal cortex, the 
calcarine sulcus, and the right lingual gyrus. These cortical regions are linked with other areas that are typically associated with spatial learning in the navigational space such as the retrosplenial cortex and the hippocampal regions (Iaria, Chen, Guariglia, Ptito, \& Petrides, 2007). The connections between them undergo prominent evolution during development. For example, the connectivity between the frontal and temporal lobules changes in 6-10-yearold children (Muftuler et al., 2012). Also, the changes in the cortical thickness were significant in the prefrontal and temporal cortex in a longitudinal study of children between 5 and 11 years old (Sowell et al., 2004).

We found that the main effect of gender favoured males in terms of the performance accuracy registered when the ARSM task requires the retention of four visuospatial items; however, we did not find any differences in the overall performance (score and span). The direct scores were also no different between males and females in the traditional tasks, except for an overall female advantage (with low effect size) in delayed visuospatial memory. The dissociation between the gender differences found in the performance accuracy of the ARSM task and the performance on the VSRD task may be attributable to the different requirements of each task. The ARSM task required immediate recall of visuospatial information presented in the navigational space for a brief period of time, whereas the VSRD (as a delayed spatial task for items presented in the near space) involved an effort of a static observer to keep in mind spatial items for a longer period of time. Some studies suggest that females may benefit from verbal strategies during the learning phase that would result in a more successful encoding (Alexander, Packard, \& Peterson, 2002; Chipman \& Kimura, 1998; Eals \& Silverman, 1994). However, female superiority was rarely observed in tasks that involved navigation (Coluccia \& Louse, 2004; Saucier, Lisoway, Green, \& Elias, 2007).

When considering a navigational short-term memory task such as the WCT, our results are supported by those found in the study of Piccardi, Palermo et al. (2014), which indicated no significant differences between males and females in the general performance of typically developing children between 4 and 11 years old. Also, no differences were found in the version of Belmonti et al. (2015), who tested children from 6 to 11 years old. In contrast, the WCT revealed a gender-related difference favouring girls in the span for routes when the test was administered to 6-10-year-olds (Piccardi, Leonzi et al., 2014). The disparity of the results related to gender differences in VSTM in the navigational space could be explained by methodological issues such as differences in the assessment procedure, the sample size, or other sample characteristics. Several researchers also discussed these issues as modulators of gender-related differences in spatial ability (Coluccia \& Louse, 2004; Miller \& Halpern, 2014; Nichelli et al., 2001; Piccardi, Palermo et al., 2014). Note that no gender-related differences were found in the pilot study of the ARSM task (the citation will be included in the final version). In addition, there were no gender differences in a large sample composed of children from three different primary schools (sample size: 268; Piccardi, Palermo et al., 2014), whereas the girls' performance advantage for the WCT was found in a smaller sample composed of children from a single primary school (sample size: 129; Piccardi, Leonzi et al., 2014). Although our sample was composed of 91 children, the selection was performed taking into account more variables to control normal development (general intelligence, general VSTM ability, and the child's behaviour) and the sample was collected from a summer school in which children from more than ten different primary schools took part. Thus, we suggest that boys and girls could perform similarly on a navigational VSTM task when we consider overall performance.

Detailed analyses of the performance considering variables associated with the type of errors committed revealed a small effect of gender limited to the groups of adults and the 7year-old group, where males showed a smaller displacement of the location pointed to with respect to the correct one. These results would suggest that males have a certain advantage 
for spatial encoding (Belmonti et al., 2015; Newhouse, Newhouse, \& Astur, 2007; Sneider, Hamilton, Cohen-Gilbert, Crowley, Rosso, \& Silveri, 2015). In addition, we found a gender difference in Level 4 for the accuracy measure; this level was characterized by a high memory load. Previous studies have suggested that an increase in the difficulty of the spatial task revealed male superiority (Canovas, Espinola, Iribarne, \& Cimadevilla, 2008; Cattaneo, Postma, \& Vecchi, 2006; Coluccia \& Louse, 2004). We should note that the absence of gender effect in Level 5 could be related to a methodological issue since the sample size was halved within this Level.

There was a positive relation between the measures of overall execution on the ARSM task and performance on the ML and VSM subtests of TOMAL. Even though the values of the correlation coefficients that showed significance were low, these results suggest that the performance on the ARSM task involved sustained attentional demands and memory processes related to simultaneous and sequential processing of spatial information (Alexander \& Mayfield, 2005; Reynolds \& Bigler, 1996). In addition, the accuracy of the performance when the task involved remembering the location of four objects was associated to the performance on the ML subtest. This result suggests that the ability to hold in mind a relatively larger number of visuospatial items in the extrapersonal space is related to the ability for simultaneous retention of spatial items in the peripersonal space (Reynolds \& Bigler, 1996). Note that the score (as an index of overall performance) was also linked to a delayed recall of the location of dots (VSRD subtest). This subtest includes the presentation of several trials for the short-term version that serves as training for the participants who should remember the trained locations after 20 minutes have passed (Reynolds \& Bigler, 1996). Hence, the performance on this navigational task could be related to the individual's ability to learn and benefit from a spatial training experience. In addition, the positive relation between the number of approximation errors committed in Level 4 and the performance on the verbal span of the Digit Backward subtest might be explained by higher working memory capacity in individuals who have reached this level of difficulty. The types of errors they made could reflect that they were close to the correct location, but they did not achieve perfect execution. This particular result also supports the differences attributed to the forward span task and the backward span task by several authors (Ramsay \& Reynolds, 1995; Reynolds \& Bigler, 1996), who argued that a greater spatial requirement in the backward version suggests visualization strategies in the performance of the backward recall. Therefore, these results taken together suggest that performance on a navigational short-term memory task requires multiple spatial abilities.

To our knowledge, the ARSM task is the first AR-based tool that has been developed to facilitate the psychological assessment of a cognitive process during development. AR facilitates good control of the visual stimuli presentation with only small modifications in any natural environment. Also, the children's perception about the experience with the ARSM task was satisfactory (the citation will be included in the final version). Similarly, the children's experience with this technology has been satisfactory in the educational field (Furio, Gonzalez-Gancedo, Juan, Segui, \& Costa, 2013; Furio, Gonzalez-Gancedo, Juan, Segui, \& Rando, 2013). Furthermore, the ARSM task overcomes the limitations of traditional assessment approaches for the study of this VSTM, which only considered the near space and static and unrealistic stimuli. In line with the growing interest in the ecological validity of the neuropsychological assessment of spatial memory (e. g., Holden, Curby, Newcombe, \& Shipley, 2010), several authors have emphasized the need to take into account the navigational space for the assessment of spatial memory (Brunsdon, Nickels, \& Coltheart, 2007; Nemmi et al., 2013; Piccardi et al., 2011).

Finally, we would like to stress the importance of early detection of spatial navigational impairments in the diagnosis of topographical disorders (Bianchini et al., 2010; 
2014; Iaria \& Barton, 2010; Iaria et al., 2009) and the relevance of spatial skill for success in school (Alloway \& Alloway, 2010; Bavin et al., 2005; Mammarella \& Cornoldi, 2014; Mammarella et al., 2013; Rourke, 1993; Szucs et al., 2013).

\section{Conclusions}

We found that the VSTM span for the navigational space increased throughout the development of children between the ages of 5 and 9 years old. The ARSM task has shown no general gender differences in the ability to perform a VSTM task in the navigational space for the age groups studied; however, males performed better when the difficulty increased. The performance on the task involved cognitive processes that are typically associated with spatial short-term memory requirements as has been positively correlated with several working and short-term memory traditional subtests.

\section{Acknowledgements}

This work was funded mainly by the Spanish Ministry of Economy and Competitiveness (MINECO) through the CHILDMNEMOS project (TIN2012-37381-C02-01) and confinanced by the European Regional Development Fund (FEDER). Other financial support was received from the Gobierno de Aragón (Departamento de Industria e Innovación), Fondo Social Europeo for Aragón, Fundación Universitaria Antonio Gargallo, and Obra Social Ibercaja. We would like to thank the following for their contributions: the "Escola d'Estiu" and especially Juan Cano, Miguelón Giménez, and Javier Irimia; the ETSInf for letting us use its facilities; the children who participated in the study and their parents who filled out the parent's questionnaires.

\section{References}

Ackerman, P. L., Beier, M. E., \& Boyle, M. O. (2005). Working memory and intelligence: the same or different constructs? Psychological Bulletin, 131, 30-60. doi: 10.1037/0033-2909.131.1.30

Alexander, A. I., \& Mayfield, J. (2005). Latent factor structure of the Test of Memory and Learning in a pediatric traumatic brain injured sample: support for a general memory construct. Archives of Clinical Neuropsychology, 20, 587-598. doi: 10.1016/j.acn.2004.12.005

Alexander, G. M., Packard, M. G., \& Peterson, B. S. (2002). Sex and spatial position effects on object location memory following intentional learning of object identities. Neuropsychologia, 40, 1516-1522. doi: 10.1016/S0028-3932(01)00215-9

Alloway, T. P. (2012). Automated Working Memory Assessment-2 (AWMA-2). London, England: Pearson Assessment.

Alloway, T. P., \& Alloway, R. G. (2010). Investigating the predictive roles of working memory and IQ in academic attainment. Journal of Experimental Child Psychology, 106, 20-29. doi:10.1016/j.jecp.2009.11.003

Andreano, J. M., \& Cahill, L. (2009). Sex influences on the neurobiology of learning and memory. Learning and Memory, 16, 248-266. doi: 10.1101/1m.918309

Bavin, E. L., Wilson, P. H., Maruff, P., \& Sleeman, F. (2005). Spatio-visual memory of children with specific language impairment: evidence for generalized processing problems. International Journal of Language \& Communication Disorders, 40, 319-332. doi: 10.1080/13682820400027750

Belmonti, V., Cioni, G., \& Berthoz, A. (2015). Switching from reaching to navigation: differential cognitive strategies for spatial memory in children and adults. Developmental Science, 18, 569-586. doi: 10.1111/desc.12240 
Bianchini, F., Incoccia, C., Palermo, L., Piccardi, L., Zompanti, L., Sabatini, U., \& Guariglia, C. (2010). Developmental topographical disorientation in a healthy subject. Neuropsychologia, 48, 1563-1573. doi: 10.1016/j.neuropsychologia.2010.01.025

Bianchini, F., Palermo, L., Piccardi, L., Incoccia, C., Nemmi, F., Sabatini, U., \& Guariglia, C. (2014). Where am I? A new case of developmental topographical disorientation. Journal of Neuropsychology, 8, 107-124. doi: 10.1111/jnp.12007

Boringa, J. B., Lazeron, R. H., Reuling, I. E., Adèr, H. J., Pfennings, L., Lindeboom. J., ...Polman, C. H. (2001). The brief repeatable battery of neuropsychological tests: normative values allow application in multiple sclerosis clinical practice. Multiple Sclerosis, 7, 263-267. doi: 10.1177/135245850100700409

Bouwmeester, L., van de Wege, A., Haaxma, R., \& Snoek, J. W. (2015). Rehabilitation in a complex case of topographical disorientation. Neuropsychological Rehabilitation, 25, 1-14. doi: 10.1080/09602011.2014.923318

Brunsdon, R., Nickels, L., \& Coltheart, M. (2007). Topographical disorientation: towards an integrated framework for assessment. Neuropsychological Rehabilitation, 17, 34-52. doi: $10.1080 / 09602010500505021$

Burgess, N. (2006). Spatial memory: how egocentric and allocentric combine. Trends in Cognitive Sciences, 10, 551-557. doi: 10.1016/j.tics.2006.10.005

Canovas, R., Espinola, M., Iribarne, L., \& Cimadevilla, J. M. (2008). A new virtual task to evaluate human place learning. Behavioural Brain Research, 190, 112-118. doi: 10.1016/j.bbr.2008.02.024

Case, R. (1992). The role of the frontal lobes in the regulation of cognitive development. Brain and Cognition, 20, 51-73. doi: 10.1016/0278-2626(92)90061-P

Cattaneo, Z., Postma, A., \& Vecchi, T. (2006). Gender differences in memory for object and word locations. Quarterly Journal of Experimental Psychology, 59, 904-919. doi: 10.1080/02724980543000079

Chipman, K., \& Kimura, D. (1998). An investigation of sex differences on incidental memory for verbal and pictorial material. Learning and Individual Differences, 10, 259-272. doi: 10.1016/S1041-6080(99)80122-8

Coluccia, E., \& Louse, G. (2004). Gender differences in spatial orientation: A review. Journal of Environmental Psychology, 24, 329-340. doi: 10.1016/j.jenvp.2004.08.006

Corsi, P. M. (1972). Human memory and the medial temporal region of the brain. Unpublished doctoral dissertation. McGill University, Montreal.

Cowan, N., Saults, J. S., \& Morey, C. C. (2006). Development of working memory for verbal-spatial associations. Journal of Memory and Language, 55, 274-289. doi: 10.1016/j.jml.2006.04.002

Eals, M., \& Silverman, I. (1994). The hunter-gatherer theory of spatial sex differences: Proximate factors mediating the female advantage in recall of object arrays. Ethology and Sociobiology, 15, 95-105. doi: 10.1016/0162-3095(94)90020-5

Fischer, R. W., \& Rose, S. P. (1996). Dynamic growth cycles of brain and cognitive development. In R. W. Thatcher, G. R. Lyon, J. Rumsey, \& N. Krasnegor (Eds.), Developmental neuroimaging: mapping the development of brain and behavior (pp. 263-279). New York: Academic Press.

Furio, D., Gonzalez-Gancedo, S., Juan, M. C., Segui, I., \& Costa, M. (2013). The effects of the size and weight of a mobile device on an educational game. Computers and Education, 64, 24-41. doi: 10.1016/j.compedu.2012.12.015

Furio, D., Gonzalez-Gancedo, S., Juan, M. C., Segui, I., \& Rando, N. (2013). Evaluation of learning outcomes using an educational iPhone game vs. traditional game. Computers and Education, 64, 1-23. doi: 10.1016/j.compedu.2012.12.001 
Gathercole, S. E. (1999). Cognitive approaches to the development of short-term memory. Trends in Cognitive Sciences, 3, 410-419. doi: 10.1016/S1364-6613(99)01388-1

Giofrè, D., Mammarella, I. C., \& Cornoldi, C. (2013). The structure of working memory and how it relates to intelligence in children. Intelligence, 14, 396-406. doi: 10.1016/j.intell.2013.06.006

Holden, M. P., Curby, K. M., Newcombe, N. S., \& Shipley, T. F. (2010). A category adjustment approach to memory for spatial location in natural scenes. Journal of Experimental Psychology: Learning, Memory, and Cognition, 36, 590-604. doi: $10.1037 / \mathrm{a} 0019293$

Iaria, G., \& Barton, J. J. (2010). Developmental topographical disorientation: a newly discovered cognitive disorder. Experimental Brain Research, 206, 189-196. doi: 10.1007/s00221-010-2256-9

Iaria, G., Bogod, N., Fox, C. J., \& Barton, J. J. (2009). Developmental topographical disorientation: Case one. Neuropsychologia, 47, 30-40. doi: 10.1016/j.neuropsychologia.2008.08.021

Iaria, G., Chen, J. K., Guariglia, C., Ptito, A., \& Petrides, M. (2007). Retrosplenial and hippocampal brain regions in human navigation: complementary functional contributions to the formation and use of cognitive maps. European Journal of Neuroscience, 25, 890-899. doi: 10.1111/j.1460-9568.2007.05371.x

Isaacs, E. B., \& Vargha-Khadem, F. (1989). Differential course of development of spatial and verbal memory span: a normative study. British Journal of Developmental Psychology, 7, 377-380.

Kessels, R. P., van Zandvoort, M. J., Postma, A., Kappelle, L. J., \& de Haan, E. H. (2000). The Corsi Block-Tapping Task: standardization and normative data. Applied Neuropsychology, 7, 252-258.

Klingberg, T., Forssberg, H., \& Westerberg, H. (2002). Increased brain activity in frontal and parietal cortex underlies the development of visuo-spatial working memory capacity during childhood. Journal of Cognitive Neuroscience, 14, 1-10. doi: 10.1162/089892902317205276

Knierim, J. J., \& Hamilton, D. A. (2011). Framing spatial cognition: neural representations of proximal and distal frames of reference and their roles in navigation. Physiological Reviews, 91, 1245-1279. doi: 10.1152/physrev.00021.2010

Kwon, H., Reiss, A. L., \& Menon, V. (2002). Neural basis of protracted developmental changes in visuo-spatial working memory. Proceedings of the National Academy of Sciences USA, 99, 13336-13341. doi: 10.1073/pnas.162486399

Leon, I., Cimadevilla, J. M., \& Tascon, L. (2014). Developmental gender differences in children in a virtual spatial memory task. Neuropsychology, 28, 485-495. doi: $10.1037 /$ neu0000054

Logie, R. H. (1995). Visuo-spatial working memory. Hove, England: Lawrence Erlbaum Associates.

Logie, R. H. (2003). Spatial and visual working memory: A mental workspace. In D. Irwin \& B. Ross (Eds.), Cognitive vision: The psychology of learning and motivation (Vol. 42, pp. 37-38). New York, NY: Elsevier Science.

Logie, R. H., \& Pearson, D. G. (1997). The inner eye and the inner scribe of visuo-spatial working memory: evidence from developmental fractionation. European Journal of Cognitive Psychology, 9, 241-257. doi: 10.1080/713752559

Mammarella, I. C., \& Cornoldi, C. (2014). An analysis of the criteria used to diagnose children with Nonverbal Learning Disability (NLD). Child Neuropsychology, 20, 255-280. doi: 10.1080/09297049.2013.796920 
Mammarella, I. C., Giofrè, D., Ferrara, R., \& Cornoldi, C. (2013). Intuitive geometry and visuospatial working memory in children showing symptoms of nonverbal learning disabilities. Child Neuropsychology, 19, 235-249. doi: 10.1080/09297049.2011.640931

Marshall, J. C., \& Fink, G. R. (2001). Spatial cognition: Where we were and where we are. NeuroImage, 14, S2-S7. doi: 10.1006/nimg.2001.0834

Mendez-Lopez, M., Mendez, M., Lopez, L., \& Arias, J. L. (2009). Sexually dimorphic c-Fos expression following spatial working memory in young and adult rats. Physiology and Behavior, 98, 307-317. doi: 10.1016/j.physbeh.2009.06.006

Miller, D. I., \& Halpern, D. F. (2014). The new science of cognitive sex differences. Trends in Cognitive Sciences, 18, 37-45. doi: 10.1016/j.tics.2013.10.011

Muftuler, L. T., Davis, E. P., Buss, C., Solodkin, A., Su, M. Y., Head, K. M., Hasso, A. N., \& Sandman, C. A. (2012). Development of white matter pathways in typically developing preadolescent children. Brain Research, 1466, 33-43. doi: 10.1016/j.brainres.2012.05.035

Nagy, Z., Westerberg, H., \& Klingberg, T. (2004). Maturation of white matter is associated with the development of cognitive functions during childhood. Journal of Cognitive Neuroscience, 16, 1227-1233. doi: 10.1162/0898929041920441

Nemmi, F., Boccia, M., Piccardi, L., Galati, G., \& Guariglia, C. (2013). Segregation of neural circuits involved in spatial learning in reaching and navigational space. Neuropsychologia, 51, 1561-1570. doi: 10.1016/j.neuropsychologia.2013.03.031

Newhouse, P., Newhouse, C., \& Astur, R. S. (2007). Sex differences in visual-spatial learning using a virtual water maze in pre-pubertal children. Behavioural Brain Research, 183, 1-7. doi: 10.1016/j.bbr.2007.05.011

Nichelli, F., Bulgheroni, S., \& Riva, D. (2001). Developmental patterns of verbal and visuospatial spans. Neurological Sciences, 22, 377-384. doi: 10.1007/s100720100068

Piccardi, L., Berthoz, A., Baulac, M., Denos, M., Dupont, S., Samson, S., \& Guariglia, C. (2010). Different spatial memory systems are involved in small and large-scale environments: Evidence from patients with temporal lobe epilepsy. Experimental Brain Research, 206, 171-177. doi: 10.1007/s00221-010-2234-2

Piccardi, L., Bianchini, F., Nori, R., Marano, A., Iachini, F., Lasala, L., \& Guariglia, C. (2014). Spatial location and pathway memory compared in the reaching vs. walking domains. Neuroscience Letters, 566, 226-230. doi: 10.1016/j.neulet.2014.03.005

Piccardi, L., Iaria, G., Bianchini, F., Zompanti, L., \& Guariglia, C. (2011). Dissociated deficits of visuo-spatial memory in near space and navigational space: evidence from brain-damaged patients and healthy older participants. Neuropsychological Development Cognitive B; Aging and Neuropsychological Cognition, 18, 362-384. doi: 10.1080/13825585.2011.560243

Piccardi, L., Iaria, G., Ricci, M., Bianchini, F., Zompanti, L., \& Guariglia, C. (2008). Walking in the Corsi test: which type of memory do you need? Neuroscience Letters, 432, 127-131. doi: 10.1016/j.neulet.2007.12.044

Piccardi, L., Leonzi, M., D'Amico, S., Marano, A., \& Guariglia, C. (2014). Development of navigational working memory: evidence from 6- to 10-year-old children. British Journal of Developmental Psychology, 32, 205-217. doi: 10.1111/bjdp.12036

Piccardi, L., Palermo, L., Leonzi, M., Risetti, M., Zompanti, L., D'Amico, S., \& Guariglia, C. (2014). The Walking Corsi Test (WalCT): a normative study of topographical working memory in a sample of 4- to 11-year-olds. The Clinical Neuropsychologist, 28, 84-96. doi: 10.1080/13854046.2013.863976 
Ramsay, M. C., \& Reynolds, C. R. (1995). Separate digits tests: a brief history, a literature review, and a reexamination of the factor structure of the Test of Memory and Learning (TOMAL). Neuropsychology Review, 5, 151-171. doi: 10.1007/BF02214760

Reynolds, C. R., \& Bigler, E. D. (1994). TOMAL Test of memory and learning: Examiner's manual. Austin, TX: Pro-Ed [In TOMAL Test de memoria y aprendizaje. Manual de interpretación (E. Goikoetxea, \& Departamento I+D de TEA Ediciones, Adapters), 2001, Madrid, Spain: TEA Ediciones].

Reynolds, C. R., \& Bigler, E. D. (1996). Factor structure, factor indexes, and other useful statistics for interpretation of the Test of Memory and Learning (TOMAL). Archives of Clinical Neuropsychology, 11, 29-43. doi: 10.1016/0887-6177(95)00027-5

Reynolds, C. R., \& Kamphaus, R. W. (2003). RIST Reynolds intellectual screening test. Interpretative manual. Torrance, CA: Western Psychological Services ([In RIST Test de inteligencia breve de Reynolds (P. Santamaria, \& I. Fernandez Pinto, Adapters), 2009, Madrid, Spain: TEA Ediciones].

Reynolds, C. R., \& Kamphaus, R. W. (1992). BASC Behavior assessment system for children, First Edition. Interpretative manual. Circle Pines, MN: American Guidance Service. [In BASC Sistema de evaluación de la conducta de niños y adolescentes. Manual de interpretación (J. Gonzalez, F. Fernandez, E. Perez, \& P. Santamaria, Adapters), 2004, Madrid, Spain: TEA Ediciones].

Rizzolatti, G., Berti, A., \& Gallese, V. (2000). Spatial neglect: Neurophysiological bases, cortical circuits and theories. In F. Boller, J. Grafman, \& G. Rizzolatti (Eds.), Handbook of neuropsychology (pp. 503-537). Amsterdam, Netherlands: Elsevier.

Rourke, B. P. (1993). Arithmetic disabilities, specific and otherwise: A neuropsychological perspective. Journal of Learning Disabilities, 26, 214-226.

Ruggiero, G., Frassinetti, F., Iavarone, A., \& Iachini, T. (2014). The lost ability to find the way: topographical disorientation after a left brain lesion. Neuropsychology, 28, 147-160. doi: 10.1037/neu0000009

Saucier, D., Lisoway, A., Green, S., \& Elias, L. (2007). Female advantage for object location memory in peripersonal but not extrapersonal space. Journal of the International Neuropsychological Society, 13, 683-686. doi: 10.1017/S1355617707070865

Sneider, J. T., Hamilton, D. A., Cohen-Gilbert, J. E., Crowley, D. J., Rosso, I. M., \& Silveri, M. M. (2015). Sex differences in spatial navigation and perception in human adolescents and emerging adults. Behavioural Processes, 111, 42-50. doi: 10.1016/j.beproc.2014.11.015

Sowell, E. R., Thompson, P. M., Leonard, C. M., Welcome, S. E., Kan, E., \& Toga, A. W. (2004). Longitudinal mapping of cortical thickness and brain growth in normal children. The Journal of Neuroscience, 24, 8223-8231. doi: 10.1523/JNEUROSCI.1798-04.2004

Szucs, D., Devine, A., Soltesz, F., Nobes, A., \& Gabriel, F. (2013). Developmental dyscalculia is related to visuo-spatial memory and inhibition impairment. Cortex, 49, 2674-2688. doi: 10.1016/j.cortex.2013.06.007

Wang, L., Cohen, A. S., \& Carr, M. (2014). Spatial ability at two scales of representation: A meta-analysis. Learning and Individual Differences, 36, 140-144. doi: 10.1016/j.lindif.2014.10.006

Zald, D. H., \& Iacono, W. G. (1998). The development of spatial working memory abilities. Developmental Neuropsychology, 14, 563-578. doi: 10.1080/87565649809540729 
Table 3

Mean Scores and Standard Deviations in the ARSM Task.

\begin{tabular}{|c|c|c|c|c|c|c|c|c|c|c|c|c|c|}
\hline & \begin{tabular}{ll} 
Gr & \\
ou & $5 \mathrm{Y}$ \\
$\mathrm{p}$ & \\
\cline { 2 - 4 }
\end{tabular} & YM & $5 \mathrm{YF}$ & $6 \mathrm{YM}$ & $6 \mathrm{YF}$ & 7YM & $7 \mathrm{YF}$ & $8 \mathrm{YM}$ & $8 \mathrm{YF}$ & 9YM & 9YF & $\begin{array}{c}25-30 \\
\mathrm{YM}\end{array}$ & $\begin{array}{c}25-30 \\
\mathrm{YF}\end{array}$ \\
\hline & & 13 & 8 & 10 & 8 & 10 & 9 & 6 & 9 & 10 & 8 & 8 & 7 \\
\hline \multirow{2}{*}{$\begin{array}{l}\text { Visuospati } \\
\text { al span }\end{array}$} & M 1. & 1.69 & 1.75 & 1.90 & 2.00 & 2.10 & 2.55 & 3.33 & $2.77 *$ & 3.30 & $3.25 * *$ & 5.37 & $4.43{ }_{*}^{* * *}$ \\
\hline & $\begin{array}{ll}S D & 0 .\end{array}$ & 0.48 & 0.46 & 0.32 & 0.0 & 0.74 & 0.53 & 1.21 & 0.66 & 0.82 & 0.46 & 0.92 & 0.97 \\
\hline \multirow[t]{2}{*}{ Score } & M 11 . & 1.08 & 11.25 & 13.30 & 13.25 & 14.30 & 14.78 & 18.67 & $17.11 *$ & 20.20 & $20.38 * *$ & 18.13 & $14.00 *$ \\
\hline & $\begin{array}{ll}S D & 2 .\end{array}$ & 2.69 & 2.71 & 2.16 & 1.28 & 4.16 & 2.05 & 4.13 & 3.65 & 4.71 & 2.72 & 3.23 & 4.12 \\
\hline \multirow{2}{*}{$\begin{array}{l}\% \text { trials } \\
\text { completed }\end{array}$} & M 67. & 77.13 & 65.41 & 73.35 & 68.79 & 72.83 & 67.7 & 72.08 & 73.08 \# & 75.05 & 75.98 " & 87.45 & 81.80 ** \\
\hline & $\begin{array}{ll}S D \quad 7 .\end{array}$ & 7.24 & 7.20 & 10.27 & 4.19 & 6.97 & 4.24 & 4.71 & 2.74 & 4.66 & 6.28 & 7.21 & 9.46 \\
\hline \multirow{2}{*}{$\begin{array}{l}\text { Non- } \\
\text { Annrox }\end{array}$} & M 3. & 3.38 & 3.50 & 3.00 & 3.25 & 3.10 & $4.67 \mathrm{~s}$ & 4.83 & 3.56 & 3.80 & 4.25 & 2.00 & $3.71 \mathrm{~s}$ \\
\hline & $\begin{array}{ll}S D & 0.4\end{array}$ & 0.96 & 1.07 & 1.15 & 0.46 & 1.10 & 1.32 & 2.04 & 0.53 & 0.79 & 1.67 & 1.07 & 2.50 \\
\hline \multicolumn{14}{|l|}{$\begin{array}{l}\% \\
\text { accurate } \\
\text { perform. }\end{array}$} \\
\hline $\begin{array}{r}\text { Level } 3 \mathrm{~N} \\
S I \\
\mathrm{n}\end{array}$ & $\begin{array}{cc}\mathrm{M} & 22 . \\
S D & 16 . \\
\mathrm{n} & 9\end{array}$ & $\begin{array}{l}2.222 \\
6.67 \\
9\end{array}$ & $\begin{array}{c}27.78 \\
25.09 \\
6\end{array}$ & $\begin{array}{c}37.04 \\
26.06 \\
9\end{array}$ & $\begin{array}{c}20.83 \\
17.25 \\
8\end{array}$ & $\begin{array}{c}41.67 \\
29.55 \\
8\end{array}$ & $\begin{array}{c}40.74 \\
22.22 \\
9\end{array}$ & $\begin{array}{c}\mathbf{5 5 . 5 6} \\
27.22 \\
6\end{array}$ & $\begin{array}{c}70.37 \text { * } \\
30.93 \\
9\end{array}$ & $\begin{array}{c}80.00 \\
32.20 \\
10\end{array}$ & $\begin{array}{l}79.17 \text { ** } \\
17.25 \\
8\end{array}$ & $\begin{array}{c}91.67 \\
15.43 \\
8\end{array}$ & $\begin{array}{c}85.71 \text { ** } \\
26.23 \\
7\end{array}$ \\
\hline Level $4 \mathrm{~N}$ & M & - & - & - & - & 66.67 & 26.67 & 50 & 27.78 & 44.44 & 50.00 & 95.83 & 76.19 \& \\
\hline & $S D$ & - & - & - & - & 0.0 & 14.91 & 19.24 & 38.97 & 33.33 & 35.63 & 11.78 & 25.20 \\
\hline & $\mathrm{n}$ & - & - & - & - & 3 & 5 & 4 & 6 & 9 & 8 & 8 & 7 \\
\hline Level $5 \mathrm{~N}$ & & - & - & - & - & - & - & 44.44 & 33.33 & 44.44 & 50.00 & 70.83 & 66.67 \\
\hline & $S D$ & - & - & - & - & - & - & 19.24 & - & 50.92 & 23.57 & 27.82 & 29.81 \\
\hline & $\mathrm{n}$ & - & - & - & - & - & - & 3 & 1 & 3 & 2 & 8 & 6 \\
\hline \multicolumn{14}{|l|}{$\begin{array}{l}\text { Appro } \\
\mathbf{x} \text {. } \\
\text { errors }\end{array}$} \\
\hline Level $3 \mathrm{~N}$ & & 1.55 & $1.33 \$ \S \S$ & 1.22 & $1.75 \$ \S \S$ & 1.12 & $1.22 \S$ & 0.50 & 0.44 & 0.30 & 0.50 & 0.0 & 0.28 \\
\hline & $\begin{array}{ll}S D & 1 .\end{array}$ & 1.13 & 1.03 & 0.97 & 0.89 & 0.99 & 0.97 & 0.55 & 0.73 & 0.48 & 0.75 & 0.0 & 0.49 \\
\hline & $\mathrm{n} \quad \mathrm{g}$ & 9 & 6 & 9 & 8 & 8 & 9 & 6 & 9 & 10 & 8 & 8 & 7 \\
\hline Level $4 \mathrm{~N}$ & & - & - & - & - & 1.0 & $2.40 \S \S$ & 0.0 & 0.67 & 1.22 & $1.0 \mathrm{~s}$ & 0.12 & 0.28 \& \\
\hline & $S D$ & - & - & - & - & 1.0 & 0.89 & 0.0 & 1.03 & 0.83 & 1.07 & 0.35 & 0.49 \\
\hline & $\mathrm{n}$ & - & - & - & - & 3 & 5 & 4 & 6 & 9 & 8 & 8 & 7 \\
\hline Level $5 \mathrm{~N}$ & & - & - & - & - & - & - & 1.50 & 3.0 & 1.0 & 2.0 & 1.0 & 1.16 \\
\hline & $S D$ & - & - & - & - & - & - & 0.70 & - & 1.0 & 1.41 & 1.19 & 1.17 \\
\hline & $\mathrm{n}$ & - & - & - & - & - & - & $2^{+}$ & 1 & 3 & 2 & 8 & 6 \\
\hline
\end{tabular}


Note. The groups are divided by both age and gender. 5YM = 5-year-old male group; 5YF = 5-year-old female group; 6YM =6-year-old male group; 6YF = 6-year-old female group; 7YM = 7-year-old male group; 7YF = 7-year-old female group; 8YM = 8-year-old male group; 8YF = 8-year-old female group; 9YM = 9-year-old male group; 9YF = 9-year-old female group; 25-30YM = 25-30-year-old male group; 25-30YF = 25-30-year-old female group; \% trials completed = percentage of trials completed successfully of the total trials performed; Non-Approx. errors $=$ number of errors committed by pointing to a location far from the goal; \% accurate perform. = percentage of successful responses performed within the first three trials of the task; Approx. errors = number of errors committed by pointing to a spatial location placed adjacent to the target location; $\mathrm{n}=$ number of participants; $\mathrm{M}=$ mean; $S D=$ standard deviation.

We highlighted the values of each gender affected by the age difference in bold. When the difference emerged in the interaction between Age and Gender factors, the Gender with the highest value is highlighted in bold.

Symbols for group effects: $\left(^{* * *}\right)$ Significantly higher as compared to $5,6,7,8$ and 9-year-old groups; $\left(^{* *}\right)$ significantly higher as compared to 5 , 6 , and 7-year-old groups; $\left({ }^{*}\right)$ significantly higher as compared to 5 and 6-year-old groups; $\left({ }^{\#}\right)$ significantly higher as compared to 7, 8, and 9year-old groups; $\left({ }^{\#}\right)$ significantly higher as compared to the 5-year-old group; $\left({ }^{\S \S}\right)$ significantly higher as compared to 8 and 9 -year-old groups and the 25-30-year-old group; $\left({ }^{\S}\right)$ significantly higher as compared to the 8-year-old group and the 25-30-year-old group; $\left({ }^{\S}\right)$ significantly higher as compared to the 25-30-year-old group.

Symbols for gender effects: $\left({ }^{\$}\right)$ Significantly higher as compared to males within this age group.

$\left.{ }^{\&}\right)$ Main effect of gender.

(†) Missing value due to data recording failure. 
Table 5

Correlation Matrix of ARSM Task and Traditional Memory Task Performance Scores controlling for age

\begin{tabular}{|c|c|c|c|c|c|c|c|c|c|c|c|c|}
\hline & & Score & $\begin{array}{l}\% \text { Trials } \\
\text { Completed }\end{array}$ & $\begin{array}{l}\text { Non-Approx. } \\
\text { Errors }\end{array}$ & $\begin{array}{c}\text { \% Accurate } \\
\text { Performance } \\
\text { Level } 4\end{array}$ & $\begin{array}{c}\text { Approx. } \\
\text { Errors } \\
\text { Level } 4 \\
\end{array}$ & ML & VSM & VSR & VSRD & $\begin{array}{l}\text { Digit Span } \\
\text { Forward }\end{array}$ & $\begin{array}{l}\text { Digit Span } \\
\text { Backward }\end{array}$ \\
\hline Visuospatial Span & $\begin{array}{c}r \\
p \\
(d f)\end{array}$ & $\begin{array}{c}.84 \\
<.0001 \\
(88)\end{array}$ & $\begin{array}{l}.10 \\
.33 \\
(88)\end{array}$ & $\begin{array}{l}.30 \\
.12 \\
(88)\end{array}$ & $\begin{array}{l}. \mathbf{3 6} \\
\mathbf{. 0 3} \\
(32)\end{array}$ & $\begin{array}{c}-.35 \\
.04 \\
(32)\end{array}$ & $\begin{array}{l}.27 \\
<.01 \\
(88)\end{array}$ & $\begin{array}{l}.24 \\
.02 \\
(88)\end{array}$ & $\begin{array}{c}.20 \\
.06 \\
(88)\end{array}$ & $\begin{array}{l}.20 \\
.06 \\
(88)\end{array}$ & $\begin{array}{l}.05 \\
.65 \\
(88)\end{array}$ & $\begin{array}{l}.11 \\
.31 \\
(88)\end{array}$ \\
\hline Score & $\begin{array}{c}r \\
p \\
(d f)\end{array}$ & & $\begin{array}{c}. \mathbf{5 0} \\
<.0001 \\
(88)\end{array}$ & $\begin{array}{l}.06 \\
.76 \\
(88)\end{array}$ & $\begin{array}{c}.71 \\
<.0001 \\
(32)\end{array}$ & $\begin{array}{l}-.32 \\
.07 \\
(32)\end{array}$ & $\begin{array}{c}.32 \\
<.005 \\
(88)\end{array}$ & $\begin{array}{c}.23 \\
.03 \\
(88)\end{array}$ & $\begin{array}{c}.18 \\
.08 \\
(88)\end{array}$ & $\begin{array}{l}.25 \\
<.02 \\
(88)\end{array}$ & $\begin{array}{l}.03 \\
.80 \\
(88)\end{array}$ & $\begin{array}{l}.10 \\
.36 \\
(88)\end{array}$ \\
\hline$\%$ Trials Completed & $\begin{array}{c}r \\
p \\
(d f)\end{array}$ & & & $\begin{array}{c}-.78 \\
<.0001 \\
(88)\end{array}$ & $\begin{array}{l}. \mathbf{5 5} \\
\mathbf{. 0 0 1} \\
(32)\end{array}$ & $\begin{array}{l}-.24 \\
.17 \\
(32)\end{array}$ & $\begin{array}{l}.16 \\
.13 \\
(88)\end{array}$ & $\begin{array}{l}.03 \\
.77 \\
(88)\end{array}$ & $\begin{array}{c}.06 \\
.55 \\
(88)\end{array}$ & $\begin{array}{l}.15 \\
.16 \\
(88)\end{array}$ & $\begin{array}{l}.002 \\
.99 \\
(88)\end{array}$ & $\begin{array}{l}-.06 \\
.59 \\
(88)\end{array}$ \\
\hline Non-Approx. Errors & $\begin{array}{c}r \\
p \\
(d f)\end{array}$ & & & & $\begin{array}{r}-.09 \\
.64 \\
(32)\end{array}$ & $\begin{array}{l}.23 \\
.24 \\
(32)\end{array}$ & $\begin{array}{l}-.18 \\
.37 \\
(88)\end{array}$ & $\begin{array}{l}.02 \\
.91 \\
(88)\end{array}$ & $\begin{array}{c}.22 \\
.26 \\
(88)\end{array}$ & $\begin{array}{l}.10 \\
.62 \\
(88)\end{array}$ & $\begin{array}{l}.24 \\
.21 \\
(88)\end{array}$ & $\begin{array}{l}.167 \\
.40 \\
(88)\end{array}$ \\
\hline $\begin{array}{l}\text { \% Accurate Performance } \\
\text { Level } 4\end{array}$ & $\begin{array}{c}r \\
p \\
(d f)\end{array}$ & & & & & $\begin{array}{l}-.62 \\
.13 \\
(5)\end{array}$ & $\begin{array}{l}. \mathbf{3 6} \\
\mathbf{. 0 4} \\
(32)\end{array}$ & $\begin{array}{l}.21 \\
.24 \\
(32)\end{array}$ & $\begin{array}{c}-.04 \\
.82 \\
(32)\end{array}$ & $\begin{array}{l}.08 \\
.66 \\
(32)\end{array}$ & $\begin{array}{l}.08 \\
.66 \\
(32)\end{array}$ & $\begin{array}{l}-.09 \\
.62 \\
(32)\end{array}$ \\
\hline $\begin{array}{l}\text { Approx. Errors } \\
\text { Level } 4\end{array}$ & $\begin{array}{c}r \\
p \\
(d f)\end{array}$ & & & & & & $\begin{array}{l}-.11 \\
.55 \\
(32)\end{array}$ & $\begin{array}{l}-.21 \\
.23 \\
(32)\end{array}$ & $\begin{array}{c}-.11 \\
.54 \\
(32)\end{array}$ & $\begin{array}{c}-.31 \\
.08 \\
(32)\end{array}$ & $\begin{array}{c}-.01 \\
.95 \\
(32)\end{array}$ & $\begin{array}{c}.45 \\
<.01 \\
(32)\end{array}$ \\
\hline ML & $\begin{array}{c}r \\
p \\
(d f)\end{array}$ & & & & & & & $\begin{array}{l}.31 \\
<.01 \\
(88)\end{array}$ & $\begin{array}{l}.29 \\
<.01 \\
(88)\end{array}$ & $\begin{array}{l}.19 \\
.06 \\
(88)\end{array}$ & $\begin{array}{l}. \mathbf{2 3} \\
. \mathbf{0 3} \\
(88)\end{array}$ & $\begin{array}{l}.10 \\
.36 \\
(88)\end{array}$ \\
\hline VSM & $\begin{array}{c}r \\
p \\
(d f)\end{array}$ & & & & & & & & $\begin{array}{l}.11 \\
.31 \\
(88)\end{array}$ & $\begin{array}{l}. \mathbf{3 4} \\
.001 \\
(88)\end{array}$ & $\begin{array}{l}.33 \\
<.01 \\
(88)\end{array}$ & $\begin{array}{c}-.03 \\
.75 \\
(88)\end{array}$ \\
\hline VSR & $\begin{array}{c}r \\
p \\
(d f)\end{array}$ & & & & & & & & & $\begin{array}{c}.63 \\
<.001 \\
(88)\end{array}$ & $\begin{array}{l}.14 \\
.18 \\
(88)\end{array}$ & $\begin{array}{l}.11 \\
.29 \\
(88)\end{array}$ \\
\hline VSRD & $\begin{array}{c}r \\
p \\
(d f)\end{array}$ & & & & & & & & & & $\begin{array}{l}.10 \\
.35 \\
(88)\end{array}$ & $\begin{array}{l}.04 \\
.71 \\
(88)\end{array}$ \\
\hline Digit Span Forward & $\begin{array}{c}r \\
p \\
(d f)\end{array}$ & & & & & & & & & & & $\begin{array}{l}-.06 \\
.59 \\
(88)\end{array}$ \\
\hline
\end{tabular}

Note. The correlation coefficients that reached significance are displayed in bold type. The performance scores on the ARSM task: Visuospatial span; Score; \% trials completed = percentage of trials completed successfully of the total trials performed; Non-Approx. Errors = number of errors committed by pointing to a location far from the goal; \% accurate performance Level 4 = percentage of successful responses performed 
within the first three trials of the task within Level 4; and Approx. Errors Level 4 = number of errors committed by pointing to a spatial location placed adjacent to the target location within Level 4. The performance scores on the TOMAL subtest: ML = Memory for Location; VSM =

Visual Sequential Memory; VSR = Visual Selective Reminding; VSRD = Visual Selective Reminding Delayed; Digit Span Forward; and Digit Span Backward. 